This introductory manual, written in nontechnical language, offers practical information of a descriptive and critical nature as to the construction, operation and maintenance of the Diesel engine and discusses the main features of its various parts and the qualities and properties of suitable fuels and lubricants. Although thermodynamics is not dealt with, the thermal principles are explained and mechanical theory also receives attention. Of great value are the numerous illustrations, which are clear and well produced.

(2) In the same category may be mentioned "Diesel and other Internal-Combustion Engines" which has been prepared with a similar end in view. In smaller scope it deals with all the types and gives more prominence to thermodynamic and other theory, but in an explanatory rather than an analytical manner.

(3) In a virile little book, Mr. Philip H. Smith, out of his wide experience as inspecting engineer to Lloyd's underwriters, deals with the excessive consumption of lubricant which characterizes the Diesel engine. The remedies and palliatives which he recommends as having been tried and proved effective are for application to engines in service ; but his remarks and conclusions are worthy of the closest attention by designers, who have the greater opportunity of developing them under favourable conditions.

The sphere of the Diesel engine was described in a lecture last year to the Royal Society of Arts by G. Mackenzie Junner, editor of the Commercial Motor, entitled "The Oil Engine and its Influence on Road, Rail and Air Transport" ( $J$. Roy. Soc. Arts, July 24, 1936). On the road, owing to its greater cost, the Diesel engine is advantageous over the petrol engine only in cases of heavy loads or long mileage. In rail transport it has to compete with its very economical rival the steam engine, but the author can point to notable advantages in that it is immediately available when wanted and can be shut down with equal promptitude, thus saving wages and fuel costs preparatory to and following the period of useful operation. In the air its merits, though as yet far from fully developed or manifested, lie in its less inflammable and less volatile fuel, in the absence of sensitive carburetters and ignition systems and in its immediate readiness for service without a prolonged period of warming up. Of these three spheres of employment, the paper offers a general survey of considerable interest.

\title{
A New Natural History
}

\section{Natural History}

Edited by Dr. Charles Tate Regan. Pp. $896+16$ plates. (London and Melbourne : Ward, Lock and Co., Ltd., 1936.) 25s. net.

$\mathrm{D}^{\mathrm{R}}$ R. TATE REGAN is to be congratulated on having succeeded in giving the student and the intelligent reading public a really well-balanced and accurate account of zoological natural history in one volume of less than a thousand pages. He is fortunate in having as his collaborators a panel of experts, each of whom is an acknowledged authority on the subject with which he is concerned. He himself deals with fishes; mammals are in the safe hands of Mr. R. I. Pocock; Mr. W. B. Alexander, of Oxford, is responsible for the bird section and Mr. E. G. Boulenger, director of the Aquarium at the London Zoo, for reptiles and amphibians, while invertebrates are split into insects and those other than insects, and are dealt with by Miss D. Aubertin and Mr. G. C. Robson respectively. A systematic arrangement of sections has been adhered to by each author, which makes the whole an easy book of reference.
The most modern system of classification has been applied in every case and it will doubtless come as a shock to many readers to find, for example, that such old and familiar friends as the lion, tiger, leopard and jaguar no longer belong to the genus Felis but have been translated to a new and very select genus Panthera, while several of the other cats such as the so-called clouded leopard and the serval have been exalted to entirely new genera. Each section has a useful introductory chapter which deals with the main attributes of the order concerned and also with related forms which have become extinct.

Apart from the letterpress, which meets both the needs of the general reader and the serious student, the volume is illustrated throughout with a collection of more than a thousand photographs of, in most cases, living animals taken by expert animal photographers in Nature and in zoos all over the world. In addition, there is a number of coloured plates reproduced from pictures by famous animal artists. Here is indeed a book of great scientific accuracy and detail which also has a popular appeal and which at the price is highly concentrated value. 